\title{
Reacción leucemoide por cáncer de cabeza y cuello. A propósito de un caso
}

\begin{abstract}
Elizabeth Lorenzo-Hernández, Fernando Salgado-Ordóñez, Jaime Sanz-Cánovas, Ricardo Gómez-Huelgas Servicio de Medicina Interna. Hospital Regional Universitario de Málaga. Málaga. España
\end{abstract}

Recibido: 09/11/2018

Aceptado: 16/01/2019

En línea: 30/04/2019

Citar como: Lorenzo-Hernández E, Salgado-Ordóñez F, Sanz-Cánovas J, Gómez-Huelgas R. Reacción leucemoide por cáncer de cabeza y cuello. A propósito de un caso. Rev Esp Casos Clin Med Intern (RECCMI). 2019 (Abr); 4(1): 13-15. doi: 10.32818/reccmi.a4n1a5.

Autor para correspondencia: Elizabeth Lorenzo-Hernández. eli.lorenzo.hernandez@gmail.com

\section{Palabras clave \\ $\triangleright$ Carcinoma epidermoide \\ $\triangleright$ Síndrome paraneoplásico \\ $\triangleright$ Cáncer de cabeza y cuello \\ $\triangleright$ Leucocitosis}

\begin{tabular}{l}
\hline Keywords \\
\hline$\triangleright$ Epidermoid cancer \\
$\triangleright$ Paraneoplastic syndrome \\
$\triangleright$ Head and neck cancer \\
$\triangleright$ Leukocytosis \\
\hline
\end{tabular}

\begin{abstract}
Resumen
La reacción leucemoide se define como un recuento de leucocitos maduros superior a 50 × $10^{9}$ células/l. Describimos un caso poco frecuente de reacción leucemoide como manifestación paraneoplásica asociada a cáncer epidermoide de cabeza y cuello, diagnosticada al excluir otras causas y que conlleva un peor pronóstico de la enfermedad. El mecanismo de producción es desconocido, aunque las teorías actuales apuntan a la producción de citocinas estimulantes de la médula ósea.

Abstract
The leukemoid reaction is defined as a count of mature leukocytes greater than $50 \times 10^{9}$ cells/l. It is described a
rare case of leukemoid reaction presented as paraneoplastic manifestation associated with epidermoid head
and neck cancer, and which has been diagnosed after excluding other causes, and which implies a worse
prognosis of the disease. The production mechanism is unknown although the current theories point to the
production of stimulatory cytokines in the bone marrow.
\end{abstract}

\section{Puntos destacados}

$\triangleright$ Se trata de un síndrome paraneoplásico asociado al carcinoma epidermoide de encía de manera poco frecuente que ensombrece el pronóstico de la enfermedad y es diagnosticado tras haber descartado otras causas de leucocitosis.

\section{Presentación del caso}

Mujer de 74 años con antecedentes personales de hipertensión arterial de larga data, hipotiroidismo y carcinoma de mama hace 15 años tratado quirúrgicamente y con quimioterapia, actualmente en remisión, sin hábitos tóxicos conocidos. En el mes de marzo de 2018, fue diagnosticada de un carcinoma escamoso bien diferenciado a nivel de la mucosa labial superior pT4NOMO. En un principio, se extirpó la masa, presentando recidiva local y rápida progresión a nivel cervical (Figura 1) a los 2 meses de la intervención, por lo que se comenzó con radioterapia con intención paliativa.

Habiendo recibido 8 sesiones de radioterapia, fue traída a Urgencias por intento de autolisis con ingesta de 20 comprimidos de valsartán/hidroclorotiazida, destacando en la analítica realizada una leucocitosis de $89,87 \times 10^{9}$ células/l (valores de normalidad: 4-15 × $10^{9}$ células/I) con 79,78 × 109 neutrófilos/l, con normalidad del resto de parámetros del hemograma. Ante este hallazgo analítico, se consultó con Hematología, que practicó un frotis de sangre periférica, no encontrando cambios en la morfología celular ni alteraciones de la fosfatasa ácida glial que sugirieran una enfermedad hematológica primaria, por lo que se intuía que el proceso era reactivo'.

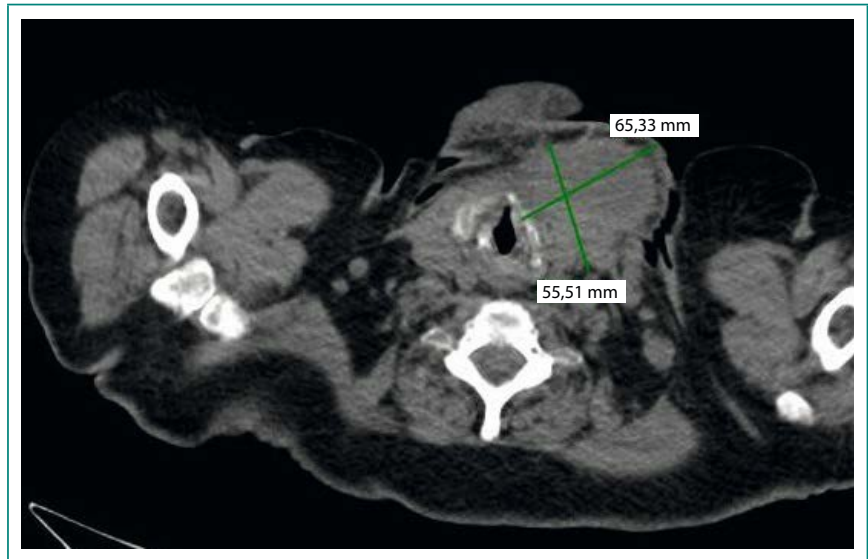

Figura 1. Progresión tumoral a nivel cervical 
Se revisó el registro histórico analítico y se observó que los niveles de leucocitos y neutrófilos ya se encontraban elevados en el momento del diagnóstico, y a los 3 meses cumplía criterios de reacción leucemoide ${ }^{2}\left(>50 \times 10^{9}\right.$ leucocitos/l) con una concentración de 50,17 × 10 leucocitos/l (Figura 2).

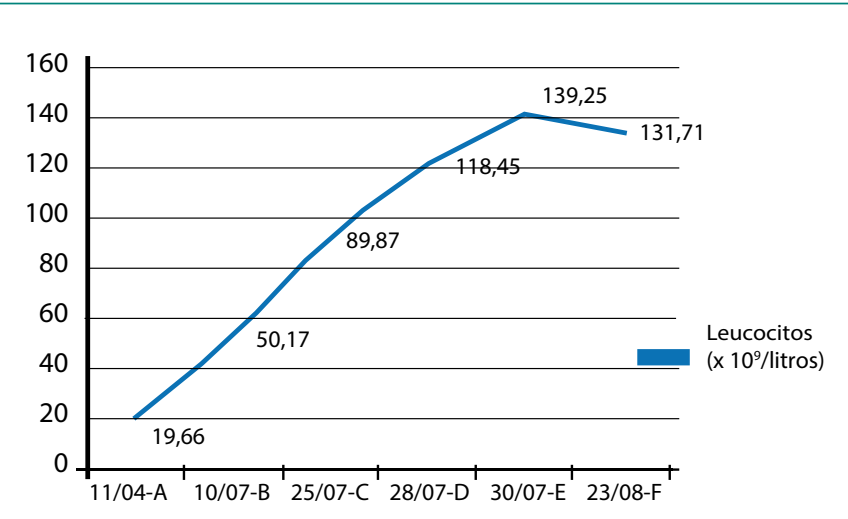

Figura 2. Evolución de la leucocitosis. A: diagnóstico de carcinoma epidermoide. B: criterios de reacción leucemoide e inicio de cefuroxima empírica. C: llegada a nuestro hospital. D: inicio de dexametasona como adyuvante analgésico. E: valor analítico más alto. F: última analítica realizada

Durante el ingreso, la paciente no presentó fiebre y se practicaron cultivos de sangre y orina que resultaron estériles (no obstante, se inició tratamiento empírico con cefuroxima por disuria), no hubo cambios respecto a las cifras de leucocitos, y no presentó otra semiología infecciosa. Se descartaron otras causas de leucocitosis, como toma de fármacos, hemorragia severa o metástasis óseas ${ }^{3}$. Se constató progresión tumoral a nivel cervical y pulmonar (Figura 3).

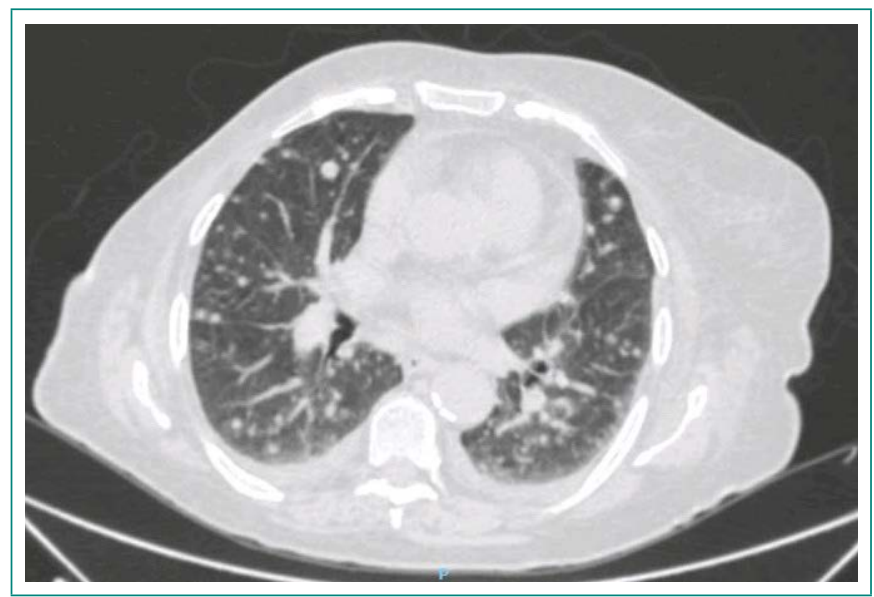

Figura 3. Metástasis pulmonares hematógenas y linfáticas

Como único síntoma, sólo refería dolor a nivel facial. Completó las sesiones de radioterapia y se inició dexametasona como coadyuvante analgésico, lo que incrementó las cifras de leucocitos hasta un máximo de 139,25 × 10\%/l. En ningún momento de la evolución se observaron síntomas de hiperviscosidad (cefalea, visión borrosa, bradipsiquia, etc.), fallo renal o fracturas patológicas. Ante el mal pronóstico de la enfermedad de base y la ausencia de datos para que las alteraciones del hemograma se debieran a un proceso hematológico primario, se desestimó la realización de biopsia de médula ósea. Finalmente, la paciente murió al mes del diagnóstico de la reacción leucemoide por progresión de la enfermedad.

\section{Discusión y conclusiones}

El cáncer epidermoide de cabeza y cuello representa el sexto lugar ${ }^{1}$ en cuanto a neoplasias malignas y se asocia a factores de riesgo como consumo de tabaco, bebidas alcohólicas, agentes virales como el virus del papiloma humano o el de Epstein-Barr, entre otros ${ }^{4}$. Afecta más a hombres, en una relación desde 2:1 hasta 4:1. El carcinoma epidermoide de mucosa bucal del labio superior pertenece a dichos tipos de cáncer. En concreto, los cánceres de cavidad oral suelen ser más agresivos debido a gran probabilidad de recidiva local y regional, con facilidad para dar metástasis a distancia en estadios avanzados (III/IV), fundamentalmente a pulmón, hueso e hígado, presentando peor pronóstico los de labio superior ${ }^{1,5}$

La reacción leucemoide se define como un recuento de leucocitos maduros superior a $50 \times 10^{9}$ células/l, que no se debe a ninguna proliferación monoclonal de precursores hemáticos. En la mayoría de los casos, se asocia a procesos infecciosos, inflamatorios o neoplásicos 3 . Por tanto, en algunas ocasiones podríamos considerar la reacción leucemoide como un auténtico síndrome paraneoplásico, sobre todo en aquéllas relacionadas con mediadores químicos secretados por el tumor. Aunque se desconoce el mecanismo etiopatogénico, algunos autores lo han relacionado con la producción de diferentes citocinas como el factor estimulante de colonias por las células del propio tumor o la activación de macrófagos mediada por mucina a través del aumento en la expresión de ciclooxigenasa-2 en neoplasias de estirpe adenocarcinoma $a^{3,6}$.

El hallazgo de este síndrome paraneoplásico asociado a un cáncer epidermoide de cabeza y cuello es excepcional ${ }^{1,7}$, no habiendo encontrado ninguno en España según la revisión bibliográfica realizada.

La reacción leucemoide ensombrece el pronóstico de la enfermedad de base, pues suele traducir progresión, como en nuestro caso, y algunos autores encuentran una mortalidad del 78\% a los 12 meses del diagnóstico de la leucocitosis, con mayor índice de malignidad y mayor tasa de metástasis ${ }^{5}$.

En nuestro caso, no pudimos determinar los niveles de GCSF, ya que no disponemos de esta técnica en nuestro centro. Además, al ser una paciente con una enfermedad avanzada de características paliativas decidimos no practicar estudios agresivos como la biopsia de médula ósea, ya que asumimos que la leucocitosis extrema se debía a la neoplasia de base.

En resumen, esta reacción leucemoide paraneoplásica asociada a cáncer epidermoide oral es una forma rara de presentación y se asocia a un peor pronóstico. El diagnóstico de este síndrome paraneoplásico es de exclusión, habiendo descartado otras causas inflamatorias, tóxicas, neoplásicas o inflamatorias. No obstante, aún es necesario contar con mayor evidencia científica para aclarar las causas e instaurar un tratamiento dirigido, aparte del propio de la neoplasia de base.

\section{Bibliografía}

1. Subramanian N, Hiremath B. Leukemoid reaction as a paraneoplastic syndrome in hypopharingeal squamous cell carcinoma with cutaneous metastasis: an exceedingly rare occurrence [Internet]. BMJ Case Reports. 2015 Dec 15. Disponible en: https://www.ncbi.n/m.nih.gov/pubmed/26670890 [Acceso 8 agosto 2018].

2. Wang D, Zhang H, Yu F, Fang B. Extreme leukocytosis and leukemoid reaction associated with the lung sarcomatoid carcinoma: an unusual case report [Internet]. Int J Gen Med. 2016 Dec 23; 10: 7-9. Disponible en: https://www.ncbi. nlm.nih.gov/pmc/articles/PMC5207432/ [Acceso 20 agosto 2018]. 
3. Granger JM, Kontoyiannis DP. Etiology and outcome of extreme leukocytosis in 758 nonhematologic cancer patients: a retrospective, singleinstitution study. Cancer. 2009; 115: 3919-3923. Disponible en: https://onlinelibrary.wiley.com/doi/epdf/10.1002/cncr.24480 [Acceso 9 septiembre 2018].

4. Stenson KM. Epidemiology and risk factors for head and neck cáncer [Monografía en internet]. En: Brockstein BE, Connor RF (Ed). Uptodate. 2018. Disponible en: www.uptodate.com [Acceso 20 agosto 2018].

5. Lee DW, Teoh DC, Chong FL. A case of nasopharyngeal carcinoma with paraneoplastic leukemoid reaction: a case report [Internet]. Med J Malay- sia. 2015 Apr; 70(2): 110-111. Disponible en: https://www.ncbi.nlm.nih.gov/ pubmed/26162391 [Acceso 8 agosto 2018].

6. Hong KH, Lee JK, Byun SJ, Jung JW, Han IW, Jung JH, Kim EJ. A case of leukemoid reaction in pancreatic ductal adenocarcinoma. Korean J Gastroenterol. 2015 Aug; 66(2): 116-121. Disponible en: https://doi.org/10.4166/ kjg.2015.66.2.116 [Acceso 20 agosto 2018].

7. Brockstein BE, Stenson KM, Song S. Overview of treatment for head and neck cancer [Monografía en internet]. En: Posner MR, Fried MP, Brizel DM, Connor RF (Ed). Uptodate. 2018. Disponible en: www.uptodate.com [Acceso 20 agosto 2018]. 